\title{
ASPECTOS DA BIOLOGIA DAS ESPÉCIES CAPTURADAS POR ESPINHEL PELÁGICO NA COSTA SUL DO BRASIL NO INVERNO DE 2001
}

\author{
SCHWINGEL, P.R. \& R.C. MAZZOLENI \\ Universidade do Vale do Itajaí (UNIVALI) \\ Centro de Ciências Tecnológicas da Terra e do Mar (CTTMar) \\ Rua Uruguai, 458. CEP 88302-202, Itajaí - SC, Brasil \\ E-mail: schwingel@cttmar.univali.br, rmazzoleni@cttmar.univali.br
}

\begin{abstract}
RESUMO
O presente trabalho descreve aspectos da biologia das espécies capturadas com espinhel pelágico na região oceânica frente ao Estado do Rio Grande do Sul, Brasil, cobrindo a área entre $30^{\circ} \mathrm{S}$ e $35^{\circ} \mathrm{S}$. Os resultados indicam o uso da área como possível sítio de alimentação para grandes predadores pelágicos como tubarões, espadartes e atuns. Os dados indicam ainda a área como um local utilizado por fêmeas de tubarão-azul Prionace glauca para o parto.
\end{abstract}

Palavras-Chaves: espinhel pelágico, sul do Brasil, predadores pelágicos.

\section{BIOLOGICAL ASPECTS OF PELAGIC LONGLINE CAUGTH SPECIES IN WINTER 2001 OFF SOUTH BRAZIL}

\begin{abstract}
The present work describes biological aspects of species caught with pelagic longline off Rio Grande do Sul State, Brazil, between $30^{\circ} \mathrm{S}$ to $35^{\circ} \mathrm{S}$. Results point this area as a possible feeding ground of pelagic predators like sharks, swordfish and tunas. Data revealed this area as a parturition location for females blue sharks Prionace glauca.
\end{abstract}

Keywords: pelagic longline, southern Brazil, pelagic predators.

\section{INTRODUÇÃO}

Surgida no Brasil durante a década de 1950 na região nordeste, a pesca com espinhel pelágico estendeu-se para as regiões sudeste no início da década de 1960, operando no porto de Santos (SP), e para os estados do sul na década de 1970 (Zavala-Camin \& Tomás, 1990). Atualmente, a frota nacional e arrendada divide-se entre os portos de Cabedelo, Natal, Recife, Santos, Itajaí e Rio Grande.Em Itajaí, o movimento de descargas oriundas de espinhal pelágico envolve cerca de 16 embarcações, sendo aproximadamente 10 sediadas neste porto. Esta frota possui um deslocamento sazonal, acompanhando os deslocamentos do recurso-alvo (i.e. espadarte), atuando no verão na região da llha de Trindade e do Arquipélago de Martin Vaz (Mazzoleni \& Schwingel, 2002) e no inverno no sul do Brasil.

Um maior desenvolvimento da pescaria dentro da Zona Econômica Exclusiva (ZEE) e em águas internacionais é meta do Brasil para os próximos anos. Nestas áreas, os estoques 
de várias espécies de peixes pelágicos oceânicos são compartilhados com outros países, o que determina uma disputa constante por maiores cotas de captura. Desta forma, é necessário um maior conhecimento dos aspectos relacionados ao comportamento e ecologia destes peixes, direcionado a um manejo adequado da pescaria. Neste contexto, o objetivo da presente investigação é agregar informações visando ampliar o conhecimento desta pescaria no que se refere a aspectos da biologia das espécies de peixes capturados por espinhel pelágico frente a região sul do país.

\section{MATERIAL E MÉTODOS}

No período compreendido entre 21 de julho e 10 de agosto de 2001, realizou-se uma viagem com o espinheleiro Basco, da empresa Estaleiro São Pedro, Itajaí, SC. A área de pesca situou-se entre as coordenadas $30^{\circ} \mathrm{S}$ a $35^{\circ} \mathrm{S}$, frente ao Estado do Rio Grande do Sul, sul do Brasil (Figura 1), entre as isóbatas de $1.300 \mathrm{~m}$ e $3.000 \mathrm{~m}$ de profundidade. Um total de 10 lances de pesca foram realizados na viagem, com média de utilização de 1.100 anzóis/

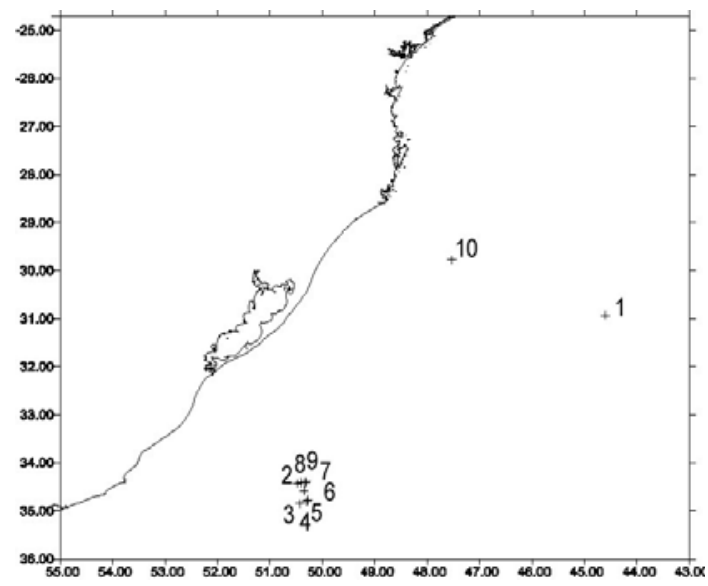

Figura 1 - Localização dos lances realizados na viagem com N.P. Basco do inverno de 2001. lance. A dinâmica do petrecho é semelhante a reportada por Mazzoleni \& Schwingel (2002).

Os indivíduos capturados foram identificados, mensurados, sexados e os estádios de maturação determinados. Dos elasmobrânquios registrou-se também o número de embriões presentes em cada fêmea e a presença ou não de esperma nos machos. As medidas obtidas para os elasmobrânquios foram: comprimento total (CT), comprimento furcal (CF), comprimento da inserção da primeira dorsal ao pedúnculo caudal (C1DPC); e para os teleósteos: comprimento total (CT), comprimento furcal (CF), comprimento inter-dorsal (CID) e comprimento maxila-furca (CMF) (Figura 2). Para as raias amostradas fora obtido também a largura de disco (LD).
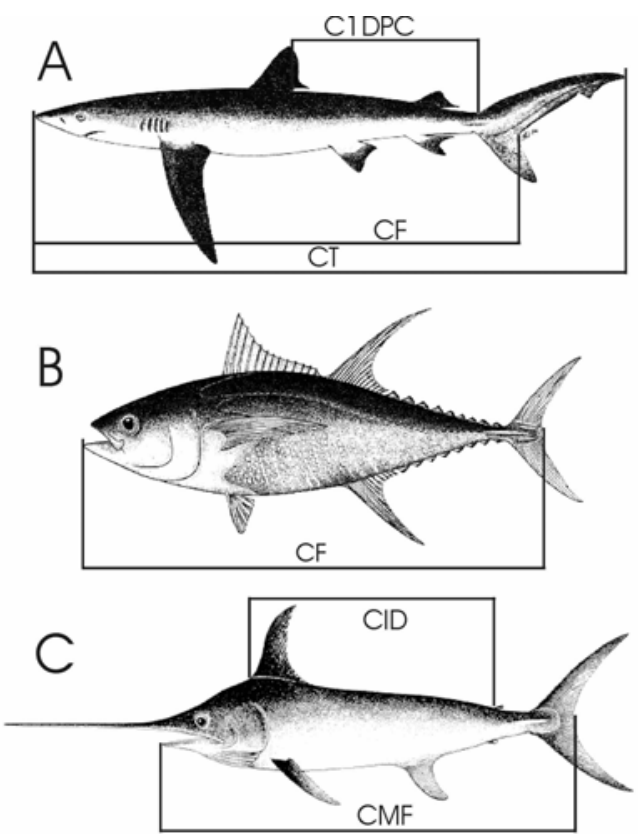

Figura 2 - Medidas biométricas tomadas para as espécies citadas no presente trabalho para A-tubarões, Batuns e C-espadarte. CT: comprimento total; CF: comprimento furcal; C1DPC: comprimento da inserção da primeira barbatana dorsal ao pedúnculo caudal; CID: comprimento inter-dorsal; CMF: comprimento maxila-furca. 
Para determinação do espectro trófico das espécies capturadas pelo espinhel, os itens alimentares foram identificados até o menor taxa possível. Dados sobre a ocorrência de presas e do grau de repleção estomacal foram usados para descrever a dieta das espécies.

\section{RESULTADOS E DISCUSSÃO}

Um total de 14 espécies foi registrado como componente da captura, sendo 6 elasmobrânquios e 8 teleósteos (Tabela 1). Destas, 5 espécies foram freqüentes na captura, i.e. tubarão-azul, espadarte e as albacorabranca, laje e bandolim.

\section{Tubarão-azul - Prionace glauca (Linnaeus, 1758)}

Ao longo do cruzeiro, capturou-se um total de 255 tubarões-azuis, sendo examinados 198 exemplares. As distribuições de frequência de comprimentos com base em 93 indivíduos mostraram que os machos $(\mathrm{n}=38)$ ocorreram em comprimentos de $120 \mathrm{a} 265 \mathrm{~cm}$ com uma moda aos $165 \mathrm{~cm}$ CT e outra aos $205 \mathrm{~cm}$ CT (Figura 3). Para as fêmeas $(n=55)$

Tabela 1 - Número de exemplares na captura total e utilizados para estudos de alimentação e reprodução por espécie.

\begin{tabular}{llc}
\hline \hline \multicolumn{1}{c}{ Nome vulgar } & \multicolumn{1}{c}{ Nome científico } & Captura \\
total $(\mathrm{n})$
\end{tabular}

os comprimentos predominantes variaram de 125 a $240 \mathrm{~cm}$ sem modas bem definidas, mostrando uma distribuição relativamente uniforme dos comprimentos amostrados. Hazin (1993) mostrou que para a região nordeste do Brasil a distribuição de comprimentos para o tubarãoazul apresenta uma distribuição com moda muito bem definida para os machos em comprimentos de $206 \mathrm{~cm}-215 \mathrm{~cm}$ CF e em 186 $\mathrm{cm}-195 \mathrm{~cm}$ CF para as fêmeas. Na presente área de estudo, as fêmeas apresentaram comprimentos superiores aos obtidos para o nordeste brasileiro conforme o trabalho de Hazin (1993) e Vaske-Jr (2000). Para possibilitar futuras investigações utilizando amostragem de desembarques de pesca industrial, onde os indivíduos são descarregados já eviscerados e sem cabeça, estimou-se a relação entre o CT e o C1DPC para machos e fêmeas separadamente (Figura 4). Nas 55 fêmeas analisadas, foi verificada a presença de marcas de cópula já cicatrizadas, caracterizando portanto nenhuma atividade de cópula recente como sugerem
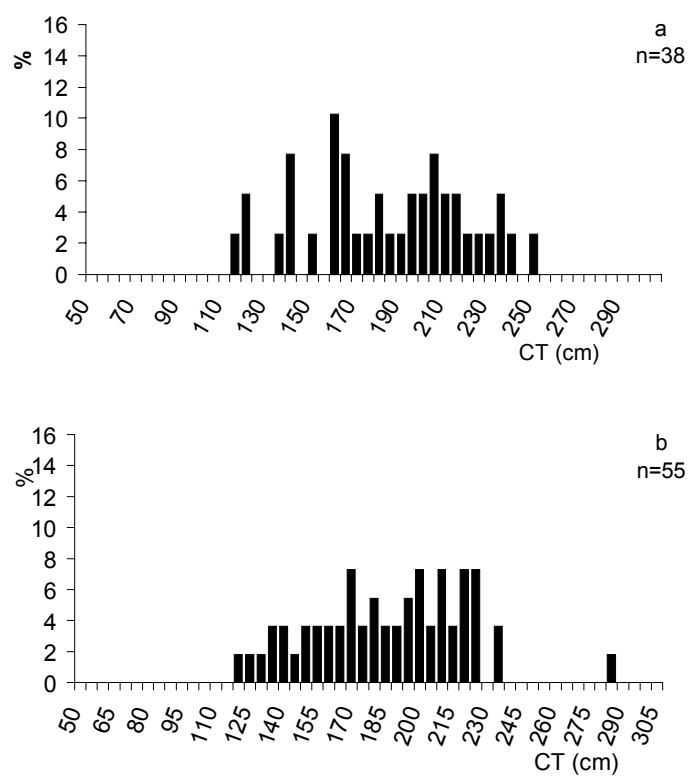

Flgura 3 - Distribuição de freqüência de comprimentos para (a) machos e (b) fêmeas de Prionace glauca durante o presente estudo. 


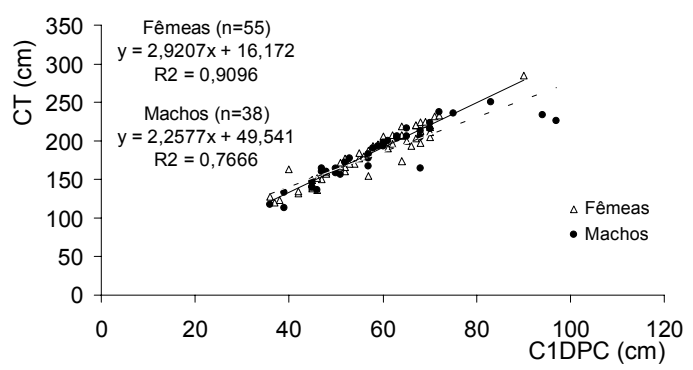

Figura 4 - Relação entre o comprimento da inserção da primeira dorsal (C1DPC) e o comprimento total (CT) obtido para $P$. glauca no presente estudo.

Stevens (1974) e Wourms (1977). A análise do aparelho reprodutor de 4 fêmeas revelou que todas estavam grávidas. Assim fora possível contar-se o número de embriões de todas mas foi possível obter informações biométricas dos embriões de apenas três delas. Para duas fêmeas (CT= $272 \mathrm{~cm}$ e $282 \mathrm{~cm}$ ), os embriões apresentavam um comprimento médio em $33 \mathrm{~cm}$ e $35 \mathrm{~cm} \mathrm{CT}$, respectivamente. Este dado confrontado com informações de Amorim (1992) indicam que estas fêmeas estavam por volta do seu oitavo ao nono mês de gestação. Para a terceira fêmea, os embriões possuíam um comprimento menor que os demais analisados, com média em $25 \mathrm{~cm}$, denotando assim, estarem no quarto mês de gravidez. Nenhuma fêmea grávida estava com ovócitos grandes em seus ovários. Na estimativa de fecundidade para as 4 fêmeas grávidas (Figura 5), encontrou-se uma média de 44 embriões por fêmea. A menor fêmea grávida possuía $272 \mathrm{~cm}$ e o menor macho maduro encontrado possuía $187 \mathrm{~cm}$, o que está próximo a estimativa de Pratt (1979) para maturação em machos que foi de $180 \mathrm{~cm}$ no Oceano Atlântico Norte. Os dados sugerem também uma relação positiva entre o número de embriões e o comprimento das fêmeas (Figura 5).

Foram analisados ao todo 119 embriões oriundos de três das quatro fêmeas grávidas, obtendo-se a distribuição de comprimentos de embriões por fêmea (Figura 6). Esses dados aliados a indicações dos próprios pescadores

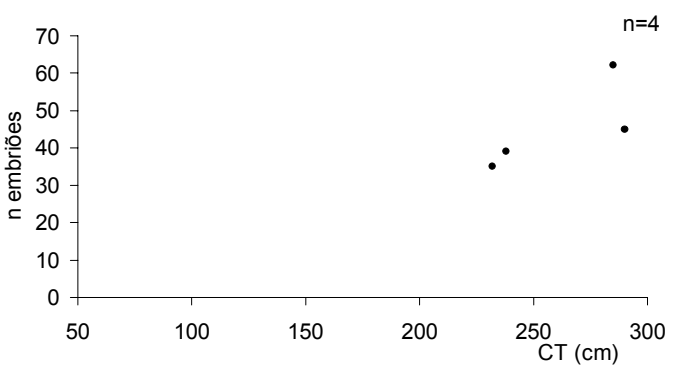

Figura 5 - Fecundidade observada para fêmeas de $P$. glauca.

revelam prováveis variações temporais no período de parto, indicando que a população não tem um período reprodutivo definido, corroborando as afirmações de Amorin (1992). A relação comprimento-peso dos embriões é mostrada na Figura 7.

Com referência a repleção estomacal, verificou-se um alto número de indivíduos com estômagos vazios, representando quase metade dos indivíduos analisados (Tabela 2). A dieta foi composta predominantemente por cefalópodes e teleósteos conforme indicado pela Tabela 3. A Tabela 4 mostra os itens alimentares identificados. Vaske Jr. \& Rincón $\mathrm{F}^{\circ}$ (1998) mostratam que o item dominante na alimentação de $P$. glauca em águas oceânicas do Sul do Brasil são lulas, assim os resultados do presente trabalho confirmam os hábitos teutófagos da espécie.

\section{Espadarte - Xiphias gladius Linnaeus, 1758}

Durante o cruzeiro foram capturados 176 espadartes. A distribuição de freqüência de comprimentos obtida para 98 exemplares é mostrada na Figura 8, revelando a dominância de indivíduos entre $120 \mathrm{~cm}$ a $220 \mathrm{~cm}$ CMF. Estes comprimentos quando colocados na equação proposta pelo trabalho de Arfelli (1996) representam exemplares com idades entre 2 e 5 anos. Uma moda menor entre $90 \mathrm{~cm}$ e $100 \mathrm{~cm}$ esteve presente na distribuição de tamanhos, sendo associada a indivíduos juvenis com apro- 


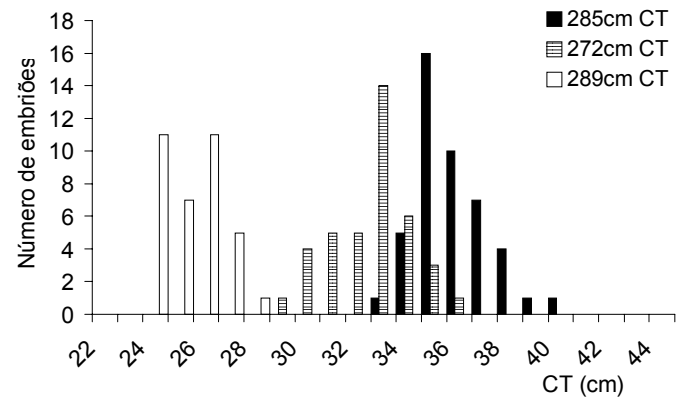

Figura 6 - Distribuição dos comprimentos em cada lote de embriões de $P$. glauca analisados no presente estudo. A legenda indica o comprimento de cada fêmea grávida amostrada da qual o lote fora retirado.

Tabela 2 - Porcentagem dos graus de repleção estomacal observados para cada espécie componente da captura. Nota: $0=$ vazio, $1=25 \%$ cheio, $2=50 \%$ cheio, $3=$ $75 \%$ cheio, $4=$ cheio.

\begin{tabular}{lcccccccc}
\hline \hline \multirow{2}{*}{ Espécie } & $\begin{array}{c}\text { Estômagos } \\
\text { analisados }\end{array}$ & $\begin{array}{c}\text { Estômagos } \\
\text { c/ conteúdo }\end{array}$ & \multicolumn{5}{c}{ Grau de repleção } \\
\cline { 6 - 9 } & $(\mathrm{n})$ & $(\mathrm{n})$ & 0 & 1 & 2 & 3 & 4 \\
\hline Anequim & 10 & 4 & - & 25,0 & 50,0 & 25,0 & - \\
Tubarão-raposa & 1 & 1 & - & - & 100 & - & - \\
Mouka & 1 & 1 & - & 100 & - & - & - \\
Tubarão-azul & 55 & 32 & 41,8 & 18,2 & 12,7 & 18,1 & 5,1 \\
Espadarte & 40 & 20 & 50,0 & 17,5 & 20,0 & 10,0 & 2,5 \\
Albacora-branca & 14 & 9 & 35,7 & 21,4 & 35,7 & 7,14 & - \\
Albacora- & 22 & 9 & 59,1 & 22,7 & 18,2 & - & - \\
bandolim & & & & & & & & \\
Albacora-laje & 20 & 14 & 30,0 & 35,0 & 10,0 & 25,0 & - \\
\hline
\end{tabular}

Tabela 4 - Dados biométricos (cm) obtidos das demais espécies de teleósteos capturadas no cruzeiro.

\begin{tabular}{lccc}
\hline \multicolumn{1}{c}{ Espécies } & $\begin{array}{c}\text { Captura } \\
\text { total }(\mathrm{n})\end{array}$ & $\begin{array}{c}\text { Exemplares } \\
\text { medidos }(\mathrm{n})\end{array}$ & $\begin{array}{c}\text { Amplitude } \\
\text { de } \\
\text { Tamanho } \\
(\mathrm{cm})\end{array}$ \\
\hline Anequim & 2 & 2 & $210-227$ \\
Dourado & 14 & - & - \\
Peixe-prego & & 20 & $48-156$ \\
Agulhão-branco & 2 & - & - \\
\hline \hline
\end{tabular}

ximadamente 1 ano de idade (Arfelli, 1996). A relação entre o CID e o CMF foi obtida como auxílio a futuros estudos de dinâmica populacional deste recurso. Isso ocorre em razão de ser o CID uma das poucas informações biométricas possíveis de serem obtidas em descargas de barcos industriais (Figura 9). As

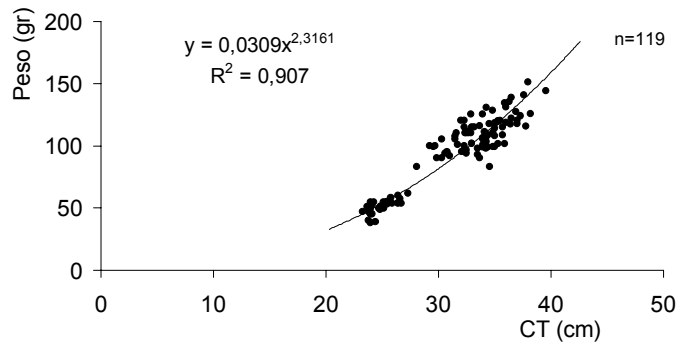

Figura 7 - Relação peso-comprimento dos embriões de $P$. glauca analisados.

Tabela 3 - Freqüência de ocorrência das presas encontradas no conteúdo estomacal das espécies analisadas no cruzeiro.

\begin{tabular}{lcccc}
\hline \hline \multirow{2}{*}{ Espécie } & \multicolumn{4}{c}{ Itens alimentares } \\
\cline { 2 - 5 } & Crustáceos & Cefalópodes & Elasmobrânquios & Teleósteos \\
\hline Anequim & 25,0 & 75,0 & - & 50,0 \\
Tubarão-raposa & - & 100 & - & 100 \\
Mouka & - & 100 & - & 100 \\
Tubarão-azul & - & 81,2 & 9,3 & 50,0 \\
Espadarte & - & 85,0 & - & 45,0 \\
Albacora-branca & - & 100 & - & 11,1 \\
Albacora- & 11,1 & 77,7 & - & 22,2 \\
bandolim & & & & \\
Albacora-laje & - & 64,3 & - & 50,0 \\
\hline \hline
\end{tabular}

Tabelas 2 e 3 indicam que os estômagos vazios representaram metade dos indivíduos amostrados e que os estômagos com conteúdo revelaram a predominância de cefalópodes e teleósteos, com destaque para as lulas do gênero Illex e Ommastrephes e os teleósteos da família Exocetidae.

\section{Atuns - Thunnus albacares (Bonaterre, 1788), T. alalunga (Bonaterre, 1788) e $T$. obesus (Lowe, 1839).}

Os atuns compuseram uma grande fração das capturas da viagem, sendo as três espécies analisadas responsáveis por $30,8 \%$ do número total de indivíduos capturados. As Figuras 10, 11 e 12 mostram as distribuições 


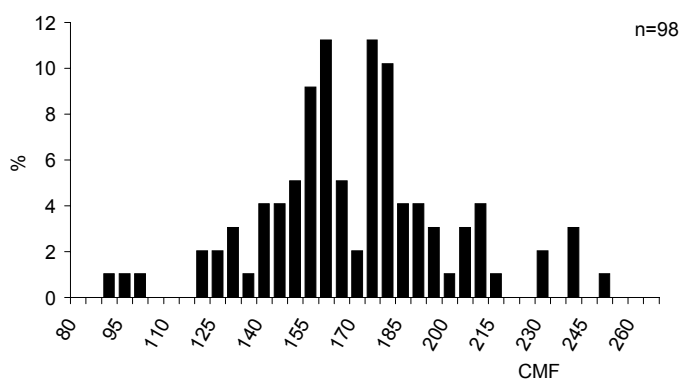

Figura 8 - Distribuição de freqüência de comprimentos para os exemplares de $X$. gladius capturados no cruzeiro. CMF em centímetros.

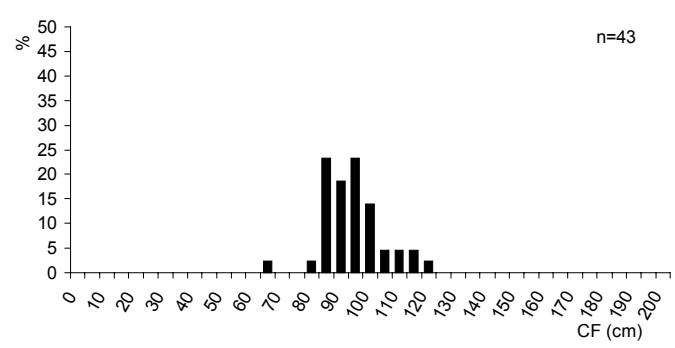

Figura 10 - Distribuição de freqüência de comprimentos para Thunnus alalunga.

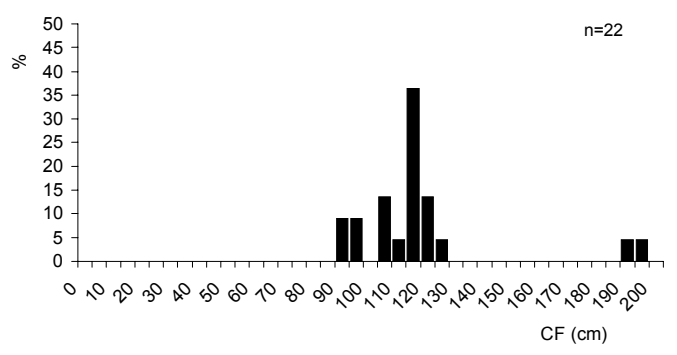

Figura 12 - Distribuição de freqüência de comprimentos para Thunnus obesus.

de freqüência de comprimentos para a albacorabranca (Thunnus alalunga), para a albacora-laje ( $T$. albacares) e para a albacora-bandolim ( $T$. obesus), respectivamente. Para T. alalunga uma moda entre $90 \mathrm{~cm}$ e $100 \mathrm{~cm}$ CF foi observada enquanto que para $T$. albacares e $T$. obesus observou-se uma moda aos $120 \mathrm{~cm}$ CF. Entretanto, T. obesus apresentou uma pequena moda aos 190 cm-195 cm CF. Dados

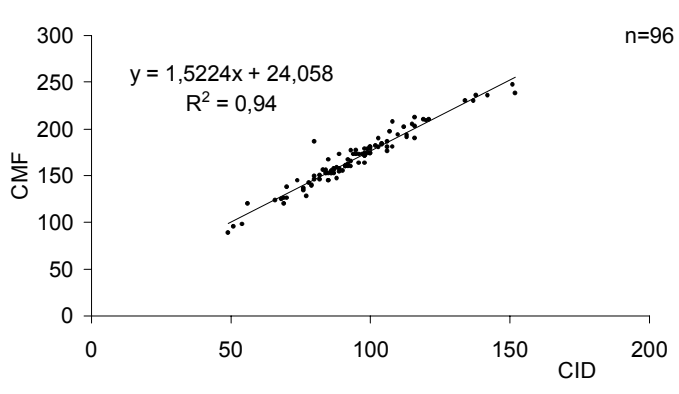

Figura 9 - Relação obtida entre o CMF e CID para os exemplares de $X$. gladius. Todas as medidas em centímetros.

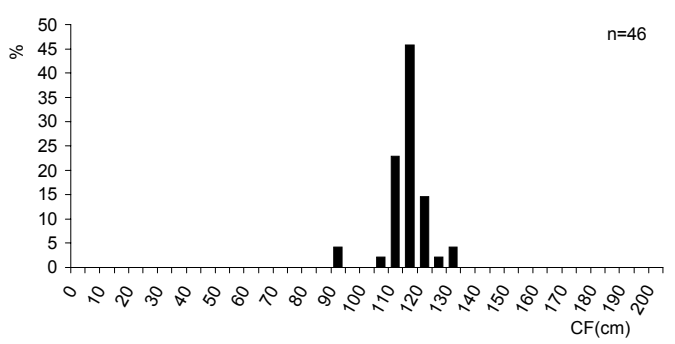

Figura 11 - Distribuição de freqüência de comprimentos para Thunnus albacares.

de Vaske Jr. (2000) relativos a distribuição de freqüência de comprimentos para estas mesmas três espécies de atuns para a região oceânica no nordeste do Brasil, mostram que $T$. albacares também apresenta uma moda aos 120 cm CF. Exceção feita para o Arquipélago de São Pedro e São Paulo, onde modas menores parecem estar associadas a indivíduos imaturos em franca atividade alimentar sobre peixes voadores (Cypselurus spp.). Para $T$. alalunga e $T$. obesus, este mesmo autor encontrou modas em comprimentos menores que os observados no presente estudo. Com relação a alimentação, os resultados ilustrados nas Tabelas 2 e 3 para T. alalunga e T. obesus estão de acordo com os obtidos por Zavala-Camim (1987), os quais mostraram um hábito predominantemente teutófago. Entretanto, este mesmo autor cita que $T$. albacares é predador predominantemente ictiófago, o que difere dos resultados do presente estudo. Isto pode ser re- 
sultado de uma maior disponibilidade do recurso Cephalopoda na região durante o período da amostragem. Entretanto, devido ao caráter eminentemente pontual da amostragem do presente trabalho uma plausível consideração sobre a existência de possível competição entre as três espécies de atuns na região de estudo seria meramente especulativa.

Deve-se salientar que outras espécies capturadas, como o anequim, mouka e o tubarão-raposa também tiveram nos cefalópodes e teleósteos, importantes itens alimentares (Tabela 3).

A alta produtividade associada à ocorrência da Convergência Subtropical no sul do Brasil nos meses de inverno resulta na agregação de diversas espécies de organismos que se aproveitam desta oferta alimentar, o que favorece a ocorrência de grandes predadores pelágicos como o espadarte, o tubarão-azul e os atuns nesta região (Garcia, 1998). Além disso, o tubarão-azul pode utilizar dessa maior produtividade para encontrar áreas de maternidade e berçário para juvenis a exemplo do que ocorre no Oceano Pacífico Setentrional (Nakano \& Nagasawa, 1996). Isto viria a fortalecer também a hipótese de migração para a espécie apresentada por Hazin (1993), que estabelece a utilização do giro oceânico do Oceano Atlântico Sul por esta espécie durante seu ciclo de vida, onde a região oceânica sul do Brasil seria utilizada pelas fêmeas grávidas para dar a luz e pelos juvenis de tubarão-azul para alimentação.

\section{AGRADECIMENTOS}

Os autores agradecem especialmente ao Sr. Marcelino Talevero do Estaleiro São Pedro, armador da embarcação Basco utilizada para o presente estudo. Agradecem ainda o mestre, Sr. Shoje Nakamura bem como toda a sua tripulação.

\section{REFERÊNCIAS BIBLIOGRÁFICAS}

Amorim, A.F. 1992. Estudo da pesca e reprodução do cação-azul Prionace glauca L. 1758, capturados no sudeste e sul do Brasil. Tese de doutorado - UNESP, 205p.

Arfelli, C.A. Estudo da pesca e aspectos da dinâmica populacional de espadarte, Xiphias gladius L. 1758, no Atlântico Sul. Tese de doutorado, UNESP.

Garcia, C.A.E. 1998. Oceanografia física. In: Os ecossistemas costeiro e marinho do extremo sul do Brasil. U. Seeliger, C. Odebrecht \& J. P. Castello Eds. Ecoscientia Ed., Rio Grande, RS.104-105.

Hazin, F.H.V. 1993. Fisheries-oceanographical study on tunas, billfishes and sharks in the Southwestern Equatorial Atlantic Ocean. Tese de Doutorado, Tokyo University of Fisheries.

Mazzoleni, R.C. \& P.R. Schwingel. 2002. Aspectos da biologia das espécies capturadas por espinhel pelágico na região sul das Ilhas de Trindade e Martin Vaz no verão de 2001. Notas Técnicas da FACIMAR, 6: 5157.

Nakano, H. \& K. Nagasawa. 1996. Distribution of pelagic elasmobranchs caught by salmon research gillnets in the north Pacific. Fisheries Science 62(6): 860-865.

Pratt Jr., H.L. 1979. Reproduction in the blue shark, Prionace glauca. Fish. Bull. 77(2): 445-470.

Stevens, J.D. 1974. The occurrence and significance of thooth cuts on the blue shark (Prionace glauca L.) from British waters. J. Mar. Biol. Assoc. U.K. 54: 373378.

Vaske Jr., T. 2000. Relações tróficas dos grandes peixes pelágicos da região equatorial sudoeste do Oceano Atlântico. Tese doutorado, FURG.

Vaske-Júnior, T. \& G. Rincón-Filho. 1998. Conteúdo estomacal dos tubarões azul 
(Prionace glauca) e anequim (Isurus oxyrinchus) em águas oceânicas no sul do Brasil. Revista Brasileira de Biologia, 58(3): 445-452.

Vazzoler, A.E.A.M. 1996. Biologia da reprodução de peixes teleósteos: teoria e prática. Ed. EDUEM.

Wourms, J.P. 1977. Reproduction and development in chondrichthyan fishes. American Zoologist, 17: 379-410.
Zavala-Camim, L.A. 1987. Ocorrência de peixes, cefalópodos e crustáceos em estômagos de atuns e espécies afins, captura-

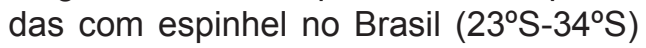
1975-1985). B. Inst. Pesca 14: 93-102.

Zavala-Camim, L.A. \& A.R.G. Tomás. 1990. A pesca de atuns com espinhel no Atlântico Sudoeste por barcos japoneses e brasileiros (1959-1979). B. Inst. Pesca, 17: 6175. 